\title{
Un encuentro peregrino entre Jorge Aguilar Mora y Gabriel García Márquez, con una nota sobre Suetonio
}

Kristine Vanden Berghe

Université de Liège / FundP Namur- Bélgica

A finales de los años setenta, el poeta, novelista, ensayista y profesor de literatura hispanoamericana Jorge Aguilar Mora (1946) empezó una investigación sobre la historia de México. ${ }^{1}$ Se encontraba entonces en Estados Unidos, lejos del México que había abandonado una década antes, en 1968. En 1979, estando en México, lejos de su patria también, Gabriel García Márquez vacilaba desde hacía años sobre qué hacer con las notas que había escrito acerca de la vida de unos latinoamericanos en Europa. El mismo año empezó a escribir Crónica de una muerte anuncia$d a$. Por lo menos, ésta es la información que ambos escritores ofrecen en los libros que publicaran más de una década después de que las primeras ideas para escribirlos hubieran surgido.

En 1990, Aguilar Mora publicó su libro con el título Una muerte sencilla, justa, eterna. Cultura y guerra durante la revolución mexicana. Es un texto que intriga y fascina, difícil de clasificar porque mezcla rasgos normalmente confinados a distintos géneros narrativos. Al mismo tiempo que es crítica literaria, incluye los ingredientes usuales de los discursos historiográfico, novelístico y autobiográfico. Si hay un elemento unificador, es el tema, que trata de la Revolución a principios del siglo veinte en el Norte de México. Los Doce cuentos peregrinos de García Márquez, que se publicaron dos años después, en 1992, son más fáciles de clasificar como cuentos, pero esta univocidad genérica es el resultado de un proceso creativo lleno de virajes.

\footnotetext{
${ }^{1}$ Aguilar Mora ha publicado también libros de poemas, tres novelas y un largo ensayo sobre Octavio Paz.
} 
Conocemos los detalles de la gestación —o la supuesta gestaciónde ambos libros porque tanto Aguilar Mora como García Márquez escribieron un texto sobre el tema, respectivamente el primer capítulo y el prólogo de sus libros. Los dos textos tienen un narrador que habla en primera persona del singular, que se parece al autor e incluyen una cantidad sorprendente de coincidencias. Aunque sea tentador pensar que García Márquez se ha inspirado en Aguilar Mora, el prólogo no permite verificar esta hipótesis, pues no lo menciona.

En este artículo analizaré las coincidencias más llamativas de los dos textos con el propósito de esclarecer algunos mecanismos literarios y más generalmente discursivos, importantes para entender cada texto por separado. En efecto, los elementos comunes potencian los significados de cada creación individual, alertando sobre posibles aspectos de contenido que, de otra manera, tal vez hubieran pasado desapercibidos. Como hilo conductor tomaré las tres palabras claves del prólogo de García Márquez titulado "Porqué doce, porqué cuentos, porqué peregrinos". Las palabras doce, cuentos y peregrinos evocan el título que Aguilar Mora dio a su primer capítulo: "La historia de los trece césares". No necesita mayor justificación el que cotejemos los numerales. Por su parte, "historia" y "cuentos" implican, entre otras cosas, una referencia al género narrativo empleado. Empiezo, sin embargo, por detenerme en las palabras "césares" y "peregrinos" que son afines ya que, en la medida en que es el atributo de "historia", la palabra "césares" tiene una función sintáctica de complemento equivalente a "peregrinos" en el prólogo garcíamarqueano.

\section{CÉSARES Y PEREgRINOS}

El adjetivo "peregrinos" en el título prologal de García Márquez se refiere, en primer lugar, al tema de sus doce cuentos que relatan los avatares durante o después de un desplazamiento de algún personaje latinoamericano en Europa. Pero el autor también emplea la palabra peregrino en el sentido de extraño. En los cuentos que nos ocupan, los viajes de los personajes son experiencias raras y García Márquez identifica el tema de la colección como "las cosas extrañas que les suceden a los latinoamericanos en Europa” (García Márquez: 6). 
En la medida en que el prólogo cuenta la génesis del libro, donde, el principal sujeto de la peregrinación no son los personajes de los cuentos sino el propio manuscrito de los doce que se guarda en la casa, viaja en los morrales de los hijos del narrador, acaba por perderse, vuelve a escribirse, a veces llega a tirarse y después de todo termina publicado. El hecho de que el calificativo "peregrino" se aplique tanto a los temas y a los personajes de la escritura como al soporte material de ésta ilustra la índole metatextual del prólogo que, al reconstruir el largo periplo de los folios que terminaron en libro, deconstruye ante el lector el proceso de la producción literaria. La selección del género en el que el tema se debía plasmar, es descrita en los mismos términos de cambio y trayectoria turbada. Al narrar la génesis de su libro, García Márquez recalca cómo abandonó varias veces una decisión por otra, cómo dudó mucho tiempo en si daría a sus textos la forma de cuentos, notas de prensa o guiones de cine.

En "La historia de los trece césares", la palabra "césares" desempeña un papel semejante a "peregrinos” en el texto de García Márquez y funciona también como detonante de un discurso autorreflexivo sobre la génesis del libro. De igual manera, ayuda a explicar la distancia entre el resultado final y el proyecto autorial inicial, pues está claro que Aguilar Mora ha vacilado entre distintos proyectos. En el último capítulo de su libro, explica que ha tomado el título Una muerte sencilla, justa, eterna, de un poema de César Vallejo (Aguilar Mora 1990: 400). Pero en el primer capítulo declara que comenzó por concebir su proyecto según el ejemplo de Suetonio en su Historia de los doce césares, libro que le sedujo por su estilo:

El pretexto fue el libro de Suetonio, Historia de los doce césares. "Me sedujo cómo disponía Suetonio, con espíritu clásico, que sabe esperar, los rasgos de los emperadores romanos según su naturaleza. Por un lado, los hechos heroicos, los decretos políticos, las acciones de gobierno; por el otro, los raptos de crueldad, los caprichos inauditos, los actos soberbios y perversos. Con un golpe de estilo, el historiador romano pasaba de una parte a otra de sus biografías con magistral serenidad" (9).

Si Aguilar Mora define su proyecto inicial en función del libro de Suetonio, es porque quería hacer los retratos de los doce, o trece, o catorce —volveré sobre el numeral- presidentes mexicanos que habían ejercido el poder de Obregón a López Portillo. También es porque empezó por concebir su libro como un libro de estilo: 
Cuando decidí imitar al historiador romano nunca creí que mi libro sería propiamente una historia, ni originalmente revelador del espíritu mexicano: ¿para quién podía ser novedad la dualidad monstruosa y humana de esos presidentes que se creen muy dioses y muy mexicanos al mismo tiempo? Ya en 1979 era un lugar común comparar, como lo hacía Octavio Paz, a los presidentes mexicanos con los tlatoanis aztecas. No, mi libro no sería de historia, ni de revelaciones biográficas. Sería simplemente un libro de estilo. Un libro donde el estilo serviría para hacer económica una imagen que ciertos mexicanos tenemos en la imaginación, en nuestra convicción y en la memoria; pero que no tenemos en la escritura (11).

Unas páginas antes, Aguilar Mora afirma que, durante los largos años de la génesis, la naturaleza original del libro no había cambiado ; sin embargo, admite que la recolección de los datos había sido "más bien caprichosa y obediente al gusto de mis momentos” (15). El cambio más importante concierne al proyectado parentesco de su libro con el de Suetonio, proyecto que abandonó en el curso de sus investigaciones: "cambió la intención inicial de reescribir, a la mexicana, el libro de Suetonio" (15).

A ambos libros les hace de preludio, por tanto, un texto que exhibe la trayectoria de la génesis, sus facetas problemáticas, sus propósitos $\mathrm{y}$, sobre todo, los caprichos de su devenir y las elecciones difíciles en lo que concierne al género.

\section{EL “YO” NARRADOR}

Quien cuenta en ambos textos introductorios es un narrador que habla en primera persona y cuyos rasgos coinciden con los del autor, de manera que las instancias del autor, narrador y protagonista parecen coincidir. En ambos casos, la decisión de escribir se explica por una experiencia personal irracional.

Un sueño hizo que García Márquez concibiera el proyecto de desarrollar el tema de los latinoamericanos en Europa: "aquel sueño ejemplar lo interpreté como una toma de conciencia de mi identidad, y pensé que era un buen punto de partida para escribir sobre las cosas extrańas que les suceden a los latinoamericanos en Europa” (García Márquez: 6). El motivo aducido por Aguilar Mora coincide con el de García Márquez al menos en dos aspectos importantes: por un lado, lo que pone en marcha 
el proceso de la escritura es una toma de conciencia de la identidad individual; por otro lado, esta toma de conciencia se relaciona con la distancia de la patria: "Para tranquilizar la mala conciencia que la ausencia de México me regalaba, concebí el remedio de conocer el país que había dejado; y de entenderlo con la ventaja, según dicen, de la distancia” (Aguilar Mora 2000: 9). Sobre todo en los primeros párrafos estos "datos" se comunican a manera de confesión:

En 1979 inicié esta historia, muy lejos de mí mismo, pero satisfecho en compañía de mis obsesiones y a gusto con el dolor y con mi terquedad por reparar los errores pasados con nuevos errores, las destrucciones irreparables con destrucciones aún más devastadoras. Ningún hijastro me retenía en el extranjero; me retenía solamente la incapacidad de tener hijos propios y la ceguera de no ver que mi esterilidad me seguía más de cerca y con mayor temeridad que cualquier ave de mal agüero (1990: 9).

Cabe señalar que la manera como los narradores presentan sus historias es bastante distinta. El tema de la identidad se enfoca más bajo sus aspectos culturales en García Márquez y es más personal en Aguilar Mora. En aquél "la distancia" se refiere a la posición geográfica del autor y se considera como el punto de partida de un proceso creativo. En Aguilar Mora, la idea de distancia también tiene connotaciones psicológicas — "lejos de mí mismo" — y se relaciona con la esterilidad biológica. Esta diferencia conlleva otra entre "Por qué doce, porqué cuentos, por qué peregrinos" y "La historia de los trece césares". Al revés de García Márquez quien relata los avatares de la creación a modo de anecdotario y cuyos hijos funcionan como guardianes de sus manuscritos - pues los llevan en sus morrales-, Aguilar Mora dramatiza las condiciones de la enunciación destacando la ausencia de hijos propios.

Pese a estas diferencias estilísticas y temáticas, el autorretrato de ambos narradores reúne los rasgos distintivos esenciales a partir de los cuales el lingüista francés Dominique Maingueneau ha identificado los llamados discursos constituyentes, filosóficos y literarios. En Le discours littéraire. Paratopie et scène d'énonciation (2004), sugiere que el lugar desde el cual estos discursos se enuncian, si bien varía en el tiempo, siempre es paradójico y se define como una complicada y difícil negociación entre el lugar y la ausencia de lugar, como una imposibilidad de estabilizarse. Un escritor literario por definición tiene problemas con la pertenencia 
unívoca, sea a un lugar, a una función o a un grupo. Se ubica en un espacio que Maingueneau llama paratópico porque resulta de una negociación difícil entre un lugar y la ausencia de lugar, un lugar parasitario que se define por la misma dificultad de establecerse: "Celui qui énonce à l'intérieur d'un discours constituant ne peut se placer ni à l'extérieur ni à l'intérieur de la société [...]. Son énonciation se constitue à travers cette impossibilité même de s'assigner une véritable 'place'" (Maingueneau: 52-53).

El autorretrato de Aguilar Mora es el de un escritor que se desplaza de un lugar a otro y que se siente extranjero en todos. Su imposible inclusión en una topía toma el aspecto de quien no encuentra su lugar o, incluso, no quiere encontrarlo. Esto último, el escritor lo dejó claro en una entrevista que le hizo Roberto García Bonilla en 2004. Cuando éste le preguntó: "¿Tu exilio de México fue fortuito o deliberado, y cómo asumes tu condición de extranjero fuera de México?”, Aguilar Mora contestó haciendo hincapié en su voluntad de vivir una vida paratópica:

Yo no me siento, ni soy, exilado, ni chicano, ni nada. Exilado, si le quitamos incluso lo político, tiene para mí la connotación de alguien que quiere regresar, que está forzado a vivir fuera. Yo no quiero regresar [...] Chicano es alguien que, sin perder su mexicanidad, se integra a otra sociedad. Yo no. Yo no quiero integrarme a esta sociedad norteamericana. Quiero ser extrańo y seguir siendo extraño. Hasta donde mi inconsciente y el sol me lo permitan (García Bonilla s.p.).

En el primer capítulo de su libro, describe su posición geográfica en estos términos: "Huía y regresaba a la ciudad de mi infancia" (Aguilar Mora 1990: 9). La paradoja está omnipresente: "No era una condena vivir en el extranjero, ni era un alivio regresar a la patria", estaba "satisfecho en compañía de mis obsesiones", "a gusto con el dolor", "con mi terquedad de reparar los errores pasados con nuevos errores, las destrucciones irreparables con destrucciones aún más devastadoras" (1990: 9). De estas afirmaciones se desprende que la condición paratópica de Aguilar Mora también incide en su estado psicológico. Asimismo, en el libro que nos ocupa su misma pertenencia al campo literario es una negociación entre el lugar y el no lugar, pues se mueve entre distintos géneros, escribiendo un libro de estilo, literario, que es al mismo tiempo y parece ser en primer lugar un ensayo histórico y cultural sobre un tema mexicano. 
El yo narrador del prólogo de Doce cuentos peregrinos tiene un perfil tan paratópico como el yo de "La historia de los trece césares", aunque la paratopía se construya de manera distinta. El movimiento que desplaza los folios del libro y que está implícito en las sucesivas elecciones del género narrativo también afecta al propio autor quien relata sus desplazamientos entre continentes durante la génesis de sus cuentos: "después de cinco años de vivir en Barcelona" (García Márquez: 5), "en nuestros viajes frecuentes" (6), "Fue en México, a mi regreso de Barcelona” (6), "emprendí un rápido viaje de reconocimiento a Barcelona, Ginebra, Roma y París" (9), "A mi regreso de aquel viaje venturoso" (10), "veinte años antes en Europa" (10), por lo cual el adjetivo peregrino se aplica igualmente al narrador de este texto quien considera su posición geográfica inestable como el punto de partida de un proceso de creación fértil que le inspiró. Su autorretrato es el de un escritor cuyo nomadismo le sugiere sus temas.

Igualmente, el sueño por el que la idea de la escritura tomó forma se presenta como un acontecimiento paratópico, aunque sea en otro sentido de la palabra. Al presentarse sońando, el narrador se sitúa en un espacio ubicado entre la vida y la muerte. ${ }^{2}$ Aparte de la forma del sueño, también su contenido es significativo:

Sońé que asistía a mi propio entierro, a pie, caminando entre un grupo de amigos vestidos de luto solemne, pero con un ánimo de fiesta. Todos parecíamos dichosos de estar juntos. Y yo más que nadie, por aquella grata oportunidad que me daba la muerte para estar con mis amigos de América Latina, los más antiguos, los más queridos, los que no veía desde hacía más tiempo (6).

El entierro es paradójico por varias razones: hay luto y fiesta, el protagonista es el muerto y el vivo, el que está rodeado de amigos y a punto de ser separado de ellos. Hallamos aquí otra faceta de la paratopía, la que se presenta bajo la forma de la separación del individuo frente al grupo. Este movimiento funciona, en el prólogo de García Márquez, como principio y origen de la creación. Observemos también que, en el fragmento citado, se unen de manera íntima la muerte y la amistad: la

\footnotetext{
${ }^{2}$ El tema de la muerte sugiere aquí otro significado de la palabra peregrino, el de "estar en esta vida, en que se camina a la patria celestial" (Diccionario de la Real Academia).
} 
muerte se imagina como la ausencia de amigos, pero simultáneamente permite que los amigos vuelvan a encontrarse. También se nota que los amigos están dichosos todos juntos: es como si su relación con el "yo" muerto determinara la amistad entre ellos.

Aguilar Mora desarrolla el mismo tema en el noveno capítulo de su libro, titulado "¿Qué es un mes de agosto si no es eso?":

El espacio simbólico de la amistad es el falansterio: el lugar donde quiero que algún día, al final de tantas vicisitudes, al final de tantos desvíos — desvaríos, iba a decir-, se reúnan conmigo mis amigos.

El sentido simbólico de la amistad es la amistad de todos mis amigos entre sí por el mero hecho de que yo los quiero a todos: el momento feliz en que todos se saluden, se reconozcan, se amen "porque tú eres amigo de Jorge y yo también".

Su sentido y su espacio son también mi muerte y mi capilla funeraria. La muerte es el revés de la amistad; así como el amor es el revés del cuerpo. La amistad no tiene el vértigo, ni el dulce torbellino de la pasión amorosa, porque la amistad siempre anda disfrazada y con su fina elección de máscaras les hace perder a las parcas el hilo de sus historias y de sus decisiones (1990: 102).

El fragmento coincide con la cita de García Márquez por cuanto narra la reunión amistosa de un grupo de gente en torno a un amigo común, carece de tono trágico o triste, $y$, sobre todo, hace aparecer paradójica e íntimamente entrelazados los temas de la muerte y de la amistad. En cierta forma, se instaura la misma relación ambigua y contradictoria entre ambas que en el texto de García Márquez ya que la muerte apela a la amistad, la reactualiza en el falansterio y la capilla funeraria, pero también se contrapone a ella porque la amistad elude a las parcas, burla a la muerte. Mientras que en el texto de García Márquez la muerte soñada del narrador prefigura los procesos individuales de degradación, el dormir y los sueños que, en calidad de temas centrales, dejan su impronta en cada uno de los doce cuentos, en el texto de Aguilar Mora la muerte imaginada del yo se enlaza con la narración de otras muchas muertes, anónimas o no, causadas por la Revolución Mexicana que es el tema principal del libro.

En ambos casos, la muerte aparece como una fuente de autoridad narrativa y el origen de la escritura. Es además como si, al igual que partici- 
par en una Revolución o hacer un viaje lejos de casa, la escritura, el propio acto de escribir, se imaginara como un proceso de envejecimiento y decrepitud, una muerte lenta aunque no tan sencilla. De esta manera se configura un lazo estrechísimo entre la actividad de contar una historia y el carácter temporal de la vida humana. Esta interpretación se refuerza cuando tomamos en cuenta que, en los dos casos, la redacción fue un proceso complicado, jalonado de decisiones difíciles.

\section{Los numerales en Aguilar Mora}

Ya he dicho que no se puede saber si García Márquez ha leído a Aguilar Mora. En cambio, en su capítulo inicial Aguilar Mora cita a García Márquez, por cuya obra ha expresado su admiración en otras ocasiones. ${ }^{3}$ En el primer capítulo de su libro dice admirarlo por su estilo, un aspecto fundamental para el escritor mexicano quien se propone precisamente escribir lo que llama un libro de estilo. Por otro lado, el estilo es también lo que más le atrae en Suetonio. De esta manera, Aguilar Mora acaba por asociar indirectamente a los dos autores, el historiador y el narrador, con base en su talento estilístico. Siempre en opinión de Aguilar Mora, el estilo del escritor colombiano es tan efectivo porque logra de manera ejemplar conseguir el objetivo social que incumbe al que practica el oficio de narrar, que consiste en convertir los hechos históricos y los abusos de los poderosos en propiedad común. Más concretamente, la literatura debe formar al lector a la crítica y educarlo a la rebeldía frente al poder. Es lo que él quiere hacer con los presidentes mexicanos:

Me parecía entonces necesario que la literatura tuviera entre sus imágenes la imagen de un presidente mexicano robándose documentos del Archivo General para ocultar su enriquecimiento con propiedad de la nación que pretendía gobernar, o la de otro quemando archivos municipales para ocultar su pasado delictuoso, o la de otro más lamiendo los zapatos del cacique omnipotente de la región para ascender en el escalafón político, o la de otro huyendo de la mujer que, como el Espíritu Santo, lo iluminó con el amor y la sífilis para refugiarse en los brazos de la hija de un terra-

\footnotetext{
${ }^{3}$ Véase su introducción a Cartucho, de Nellie Campobello (Aguilar Mora 2000: 9 et passim).
} 
teniente astuto y rico... y así todos y cada uno con sus dos rostros. Jano y la historia de México.

Ambos rostros están en la boca de los rumores de todos nuestros días, en las calles, en los hogares, en los documentos, en los libros de memorias de contemporáneos suyos; pero no están en la literatura, y la literatura en estas historias de vileza y de esfuerzo tiene, según yo, una tarea decisiva: convertir los hechos históricos en acontecimientos lingüísticos y en propiedad colectiva y anónima. Esa función cotidiana y luminosa de la literatura permite transfigurar el dolor colectivo en voluntad, y la voluntad en imperativo moral, sobre todo en los momentos en que el tiempo histórico mismo oscurece nuestro futuro más inmediato. (Aguilar Mora 1990: 11).

A fin de realizar ese proyecto, Aguilar Mora se propone imitar a Suetonio y esbozar el perfil de doce presidentes mexicanos. El tema de los numerales en este contexto parece bastante banal: el libro de Suetonio se titula Historia de los doce césares y Aguilar Mora quiso crear una filiación, esbozando una serie de retratos semejante de los gobernadores mexicanos. Sin embargo, la época histórica que a él le interesaba era irreductible a doce y contaba, exactamente, trece presidentes. Esta discrepancia es otro detonador del relato metatextual sobre la gestación del libro.

El autor relata de manera detallada cómo estas cifras se relacionan con su texto. Tanto entusiasmo le causaba la idea de copiar a Suetonio que incluso quería hacer trampa con la historia de México:

De Obregón a López Portillo había trece mandatarios, no doce, pero al hacer mi primera cuenta decidí excluir a uno, a cualquiera, de los tres que ocuparon la presidencia durante el Maximato para que el número coincidiera con el número de césares de Suetonio (10).

Con esto confirma la prioridad de las relaciones intertextuales sobre la realidad, y cuestiona la necesidad de que el texto sea un reflejo de la realidad, sea cual fuere la intención del autor. En otras palabras, un elemento co-textual, del contexto textual, prevalece sobre un elemento del contexto histórico. Se trata de una opción significativa en cuanto a la escala de prioridades manejada por Aguilar Mora en su concepción inicial del texto.

Luego, le asaltaron los escrúpulos, reconoció que era imposible reducir la serie presidencial a doce y decidió optar a favor de la "verdad" histórica de los trece presidentes: 
En ese momento pensé también que quizás no tenía que hacer ninguna trampa y que en vez de la historia de los doce césares podía hacer la de trece, sin que por ello traicionara el espíritu de mi imitación de Suetonio. Como título, La historia de los trece césares no estaba del todo mal y, si se perdía la alusión evangélica del número doce, se ganaba en cambio el aire maléfico del trece (10).

El cambio de numeral implica un cambio de prioridades en la confección del texto, porque la fidelidad a un texto anterior, el deseo de establecer una relación intertextual con Suetonio, se ve desplazada por una voluntad de fidelidad a la historia. No obstante, la subordinada exclusiva introducida por el nexo "sin que" señala que la fidelidad a Suetonio sigue presente como criterio. Aguilar Mora cree que, al optar a pesar de todo por el número trece, no traicionará a Suetonio, con lo cual afirma que el lazo intertextual continúa siendo importante. Incluso después de que el propósito de rivalizar con Suetonio se hubiera abandonado, el proyecto de imitar al historiador romano sigue en pie. Lo quiere emular al tratar de la misma manera las etapas históricas fundamentales y los detalles y al acumular las fuentes con una predilección hacia las obras menores. También llama la atención la doble connotación, evangélica y maléfica, que el escritor atribuye a los numerales.

Al final del capítulo, Aguilar Mora retoma el tema, dejando definitivamente clara su opción por el trece y confirmando el abandono de su proyecto inicial que giraba en torno a las vidas presidenciales a favor de la composición de un retablo más pintarrajeado en el que los grandes personajes se verían cotejados por un sinnúmero de figuras anónimas y secundarias:

Para nuestra vida, la causalidad es la hija de la coherencia incomprensible de la totalidad; para nuestra vida, la casualidad es el excedente constante de esa coherencia, que no cabe en sí misma, pues de conformarse con su perfección nada se movería, nada sucedería. Siempre sobra algo del todo, y es siempre singular : nunca hay solo doce césares, los césares siempre son trece. Sin el último, o el primero, los otros doce nunca sabrían de su amable simetría (19).

Conociendo la importancia simbólica que revisten las cifras para Aguilar Mora, sabiendo de las connotaciones evangélicas que atribuye 
al número doce, simétrico y asociado con Dios, sabiendo también que el trece lo considera como un número maléfico, necesario y connotado con el poder corrompido, es difícil creer que sea una casualidad que su libro se compone de 52 capítulos, o sea cuatro veces trece. De esta manera, Aguilar Mora logra integrar en el mismo andamiaje de su libro un número evangélico, el cuatro, y uno maléfico, el trece. Se podría leerlo como una clave interpretativa de la idea de que, en sus dos rostros de Jano, en el acto de escribir y en el de luchar - las letras y las armas - lo maléfico y lo benéfico se reúnen inevitablemente.

\section{Los numerales en García Márquez}

Desde cierto punto de vista, el discurso que teje García Márquez en su prólogo acerca de los numerales es opuesto, ya que casi no hace otra cosa que relatar la larga cadena de extravíos y reencuentros que desemboca en el numeral doce al que presenta como una cifra enteramente casual.

El prólogo arranca con las dos frases siguientes que son ilustrativas del texto en su totalidad por cuanto en él abundan las cifras: "Los doce cuentos de este libro fueron escritos en el curso de los últimos dieciocho años. Antes de su forma actual, cinco de ellos fueron notas periodísticas y guiones de cine, y uno fue un serial de televisión” (García Márquez: 5, subrayado mío). En el texto las cuentas cronológicas de García Márquez están tan detalladamente consignadas que sorprenden, sobre todo después de tantos años y de tantas vicisitudes, lo cual nos pone en alerta. $\mathrm{Y}$ con razón porque, contrariamente a su finalidad aparente de querer testificar la autenticidad de los datos, resulta que no son fidedignas: en sus notas de prensa de los años ochenta García Márquez hizo declaraciones no del todo compatibles con la información contenida en el prólogo (Joset: 20). Las fechas son otra de las trampas cronológicas que abundan en la biografía del "manipulador del tiempo" (12 y 17) que es García Márquez. Si las fechas propuestas no son históricamente correctas, no hay ninguna razón para creer en la facticidad de los otros ingredientes del relato ni que el doce sea un numeral casual.

Si el título "Porqué doce, porqué cuentos y porqué peregrinos", presenta lo que en el texto se narra como verídico e histórico, el otro título que le precede, "Prólogo", impreso en letras más grandes, llama la aten- 
ción sobre el aspecto metatextual de ese primer texto de la colección. En calidad de prólogo es un texto marco que se distingue de los textos enmarcados, los cuentos. Pero lo que acabo de sugerir acerca del valor no verídico del prólogo perturba esta relación ya que relativiza la diferencia entre los dos estatutos textuales. El pacto de veracidad en el que parece basarse resulta finalmente ser un pacto de verosimilitud. Al leer el prólogo de esta manera, su naturaleza cambia y de repente se transforma en el cuento número trece. Esta lectura es apoyada por las numerosas coincidencias temáticas con los cuentos. De la misma manera que los cuentos, el prólogo habla de la soledad de un personaje latinoamericano que estuvo viajando por Europa. Este narrador personaje del prólogo se debe apartar de sus amigos, un desplazamiento que afecta igualmente a los personajes latinoamericanos de sus doce cuentos que se sienten solos en una Europa racional e inhóspita. El prologuista aún relata que el proyecto del libro surgió después de una estancia en Europa y que el proceso de redacción termina después de que el narrador hizo un "viaje de reconocimiento" a varias ciudades europeas. El narrador personaje es, por consiguiente, otro latinoamericano que se desplaza por el Viejo Mundo.

De este modo se introduce asimismo la pareja doce / trece o, si aplicamos la valoración de Jorge Aguilar Mora, la pareja evangélico / maléfico. No es difícil reconocer lo maléfico en los cuentos ya que describen al Viejo Mundo en sus aspectos más decadentes y tratan de la muerte como uno de los temas más fundamentales. El número doce, por otra parte, puede relacionarse con las peregrinaciones que llevan a algunos personajes a la Roma pontifical.

\section{Historia y RELATOS, UNA CUESTIÓN DE GÉNEROS}

El libro de García Márquez, una colección de cuentos, no parece tener mucho que ver con el de Aguilar Mora, un ensayo histórico que se presenta como un libro de estilo. A ambos, sin embargo, les preludia un texto que relata de manera aparentemente verídica la génesis del libro como un proceso largo, difícil y accidentado. En los dos textos los respectivos narradores hacen resaltar sus propios rasgos paratópicos, en el sentido espacial, identitario o psicológico. En los dos, los numerales funcionan como una clave a partir de la cual el lector puede interpretar el 
estatuto que ambos autores confieren a sus textos prologales así como a los textos a los que sirven de introducción.

En el prólogo de García Márquez, el juego con las cifras abre grietas en la aparente veracidad del texto y suscita la desconfianza del lector. Unido a las coincidencias temáticas con los cuentos hace bascular el estatuto del prólogo como texto marco y legitima su lectura como un texto enmarcado, de ficción. De manera sutil acaban por borrarse las fronteras entre veracidad y verosimilitud, entre metatexto y texto, entre historia y ficción. García Márquez parece sugerir que la crítica y la historia literarias, los relatos de la génesis, son tan construidos y tan subjetivos como los propios textos de ficción.

El texto de Aguilar Mora se construye sobre la misma desconfianza hacia las distinciones tradicionales entre géneros y entre verdad y ficción. De una manera parecida, mediante un discurso sobre los numerales doce y trece, más explícito que en García Márquez, el escritor mexicano llama la atención sobre el carácter subjetivo de su texto que, aunque trate de la historia mexicana, no es un reflejo de la realidad sino una construcción que resulta de una serie de decisiones y gustos personales. En este sentido se entiende que define su libro como un libro de estilo más que como un documento historiográfico tradicional. Aguilar Mora se toma la libertad de saltar de un episodio de la historia revolucionaria a sus obsesiones personales y de partes más historiográficas a otras, de índole poética, desnaturalizando de esta manera la evidencia de las divisiones genéricas y minando la posibilidad de la representación verdadera. Ya que en su texto el acontecimiento se transforma siempre en experiencia vital, incita al lector a cuestionar el estatuto epistemológico del conocimiento histórico. El constante entretejimiento entre la información histórica y las reflexiones sobre el proceso de la narración, la inbricación de los niveles enunciado, comentario sobre el enunciado, metacomentario- no hace otra cosa que ilustrar la reflexividad fundamental del discurso de Aguilar Mora, un rasgo que lo vuelve profundamente literario (Maingueneau: 63). ${ }^{4} \mathrm{Al}$ reivindicar a Suetonio y al desarrollar paralelamente un discurso

${ }^{4}$ Cuando García Bonilla preguntó a Aguilar Mora si existía una conexión entre Una muerte y una novela del autor, Los secretos de la aurora en cuya narración se impone una reflexión permanente que le da un aire ensayístico, contestó: "Sí, la hay. Y es parte de la propuesta de esos libros: que los lectores sientan la fuerza de esas conexiones y que esa fuerza los lleve a las encrucijadas y por los pasadizos secretos. Y que los llevará incluso a 
acerca de los numerales doce y trece, Aguilar Mora subraya que la línea entre historia y literatura es borrosa y que toda escritura es una construcción personal. Sobra decir que esto vale tanto o más para ese proceso de reescritura que es la lectura. Si la interpretación que precede puede parecer muy libre, creo haber demostrado que la poética de los dos escritores legitima e, incluso, invita a hacer pleno uso de tal libertad.

\section{Bibliografía}

Aguilar Mora, Jorge. Una muerte sencilla, justa, eterna. Cultura y guerra durante la revolución mexicana. México: Era, 1990. . "El silencio de Nellie Campobello", en Cartucho. Relatos de la lucha en el Norte de México. México: Era, 2000. 9-42.

García Bonilla, Roberto. "Los Misterios del Alba. Entrevista con Jorge Aguilar Mora”. en Espéculo. 27 (julio-octubre 2004).

García Márquez, Gabriel. Doce cuentos peregrinos. [Primera edición 1992]. Madrid: Debolsillo, 2005.

Joset, JACQues. "Introducción", en Cien años de soledad. Madrid: Cátedra, 2003. 9-80 (Letras Hispánicas).

Maingueneau, Dominique. Le discours littéraire. Paratopie et scène d'énonciation. Paris: Armand Colin, 2004.

SuÉtone. Vies des Douze Césars. Traduit et commenté par Pierre Klossowski, préfacé et annoté par Perrine Galand-Hallyn. Paris: Livre de Poche, 1990.

un poema como Stabat Mater (1996). Mi poesía está conectada también con el ensayo, con la novela, con los cuentos que nunca he escrito y que nunca escribiré, y con las obras de teatro que estoy escribiendo y que no sé si terminaré" (García Bonilla s.p.). 